\title{
FTA: A Stumbling Bloc towards Global Free Trade
}

\author{
Qiong Wang ${ }^{1}$ \\ ${ }^{1}$ School of Economics, Northwest Minzu University, Lanzhou, China \\ Correspondence: Qiong Wang, School of Economics, Northwest Minzu University, Lanzhou, China. E-mail: \\ wangqiong2008@foxmail.com
}

Received: November 22, 2019

Accepted: December 10, 2019 Online Published: December 15, 2019

doi:10.5539/ijef.v12n1p22

URL: https://doi.org/10.5539/ijef.v12n1p22

\begin{abstract}
This paper examines the impact of free trade areas (FTAs) on the world trading system. It uses a partial equilibrium framework among three countries where Cobb-Douglas utility function is applied. It is found that FTAs are primarily detrimental to multilateral trading system and are stumbling blocs to global free trade (GFT), whether in a symmetric or an asymmetric case. This conclusion is based, firstly, upon the findings that the utility of member countries in a FTA are higher than status quo, so they are interested in forming a FTA, and secondly, after forming a FTA, they don't have incentive to let the third country join in since their utility would be lowered. In addition, this paper shows that when there are two large countries and a small one, it is more profitable for one large country to form a FTA with the small one instead of the other large one.
\end{abstract}

Keywords: free trade areas, global free trade, partial equilibrium, equilibrium utility

\section{Introduction}

\subsection{Background}

The wave of Regional trade arrangements (RTAs), such as free trade areas (FTA) and customs unions, has been attached considerably substantial attention by economists. The surge in RTAs has continued unabated since the early 1990s. By November 2019, some 481 notifications of RTAs have been received by WTO. The overall number of RTAs in force has been increasingly steadily to 302 , a trend likely to be strengthened by the many RTAs currently under negotiations. Of the 481 notifications of RTAs, free trade agreements (FTAs), partial scope agreements and economic integration agreements account for over $90 \%$, while customs unions account for less than 10\% (World Trade Organization, 2019). So this paper will focus on FTAs, which are much more common and have attracted more attention than customs unions.

A free-trade area is a trading bloc whose member countries have signed a free-trade agreement, which eliminates tariffs, import quotas, and preferences on most goods and services traded between them. The aim of free trade areas is usually to remove barriers between member countries so as to increase trade. As global free trade (GFT) is a welfare-improving and optimal state for all the countries as a whole, much research has been made on whether FTA is a building bloc or a stumbling bloc to GFT. Nevertheless, over the past three decades, no consensus has been reached.

For many economists, it seems that FTA is more likely to be a stumbling bloc to GFT than a building bloc. As Bhagwati (1991) puts forwards, FTA is analyzed under static and dynamic time-paths, and even when FTAs can improve the welfare of member countries in static they may be a stumbling bloc for further liberalization. Levy (1997) shows that bilateral agreements in a median voter model may finally lead to the damage of multilateral trade agreements. And McLaren (2002) finds that when considering the negotiating costs and sector-specific sunk investments, multilateral trading system may work at first, but a reduction in member countries' gain from export can make it infeasible in the end. Yi (2000) finds that although the formation of a free-trade area is a Pareto improvement, FTA won't lead to global free trade in the end because of free-riding problems. What's more, Krishna (1998) and Panagariya (1996) also view FTA as a stumbling bloc to attain global free trade.

On the other hand, Cadot (1999) and Freund (2000) both illustrate that regionalism can provide a way towards GFT. Ornelas (2005) uses an oligopolistic-political-economy model with endogenous tariffs of FTA members, shows that FTAs are beneficial to the multilateral trading system. Bagwell and Staiger (1999) show that FTA may be a stumbling bloc in the short run, but ultimately a building bloc in the long run. While Cheong and Wong (2010) find the results cannot be clear-cut. And Riezman (1990) finds that if there are one large country and 
some small ones, FTA can be a building bloc to attain global free trade. But if the countries are of relatively equal size, then FTA is a stumbling bloc.

When it comes to the issue of society welfare or utility, most of the research has focused on consumer surplus, producers' profit and governments' tariff revenue. So it seems that there is a surprising absence of considering utility from the respect of consumption level.

This paper uses a modified version of the partial equilibrium framework developed by Saggi and Yildiz (2011), and Cobb-Douglas utility function is applied to simplify countries' utility into the function of their consumption level. This paper examines whether free trade areas are building blocs or stumbling blocs to global free trade both in symmetric and asymmetric case. In the general model, we obtain the consumption level and utility level for each country under GFT, status quo and FTA case respectively, then specify the model by analyzing symmetric and asymmetric case. And the results show that FTA is a stumbling bloc to GFT no matter it is under symmetric case or asymmetric case.

\subsection{Literature Review}

Ornelas (2005) use an oligopolistic-political-economy model with endogenous tariffs of FTA members and decisions to form FTAs, shows that FTAs are beneficial to the multilateral trading system. The paper considers consumer surplus, producers' profit and governments' tariff revenue. He first shows that FTAs induce their member governments to lower their external tariffs, which strictly increase trade flows among FTA members, and trade flows between FTA members and non-members. So this will improve the gains for non-members while may not ensure the gains for FTA members. However, the governments will adopt welfare-improving agreements instead of considering their political motivations. So the FTA members gain as well.

Bagwell and Staiger (1999) use a three-country world model and identify three opposing effects of preferential agreements on multilateral trade system. The relative strengths of these three effects determine the impact of preferential agreements on multilateralism. When the countries are sufficiently impatient, the formation of free trade areas will lead to an overall deterioration in multilateral tariff cooperation. So free trade area is a stumbling bloc in transition but a building bloc in the long run. Tariffs will increase when two countries' trade flows are small before forming a FTA, but will be lowered after countries forming a FTA in order to reduce the tariff cost due to larger trade flows. Based upon an extensive data set covers most of the world trade over the past 60 years and 240 RTAs, Bernhard and Macro (2011) point out that RTAs are building blocs to multilateral trade liberalization. Baldwin (2006) describes what the final steps to global free trade might look like, and points out that offshoring can create a force that encourages regionalism to multilateralism.

However, Levy (1997) shows if FTA cannot lead to further multilateral liberalization, then FTA can be viewed as a stumbling bloc to global free trade. Levy uses a framework where the median voter plays a pivotal role in making trading decisions. It shows that bilateral agreements between countries with similar endowments offer disproportionately large gains to key agents in a country, which raise their reservation utility over the multilateralism level. As key agents in a country don't have incentive to reach a utility under their reservation level, FTA is detrimental for further multilateral liberalization. In addition, he mentions that bilateralism can never provide political support for multilateralism, which also strengths the points of the paper.

Some papers also point out that the results cannot be clear-cut. Cheong and Wong (2010) use a three-country world model and each country has a numeraire good produced by competitve firms and a homogeneous good produced by oligopolist firms. The authors value the utility of each country from the perspective of producers, and represent utility by producers' profit. If global free trade is finally reached by WTO path but cannot be reached by FTA path, then FTA is said to be a stumbling bloc. However, if global free trade is finally reached by FTA path but cannot be reached by WTO path, then FTA is said to be a building bloc. The paper compares the utility level under WTO path and FTA path, and it is found that either path can be feasible under certain situations. So the results cannot be clear-cut. Saggi and Yildiz (2011) apply a partial equilibrium framework in a three-country world. Preferences over the two goods are quasilinear, while firms compete in quantities and make independent decisions regarding how much to sell in each market. The paper shows that results are ambiguous: when the degree of cost asymmetry among three countries is small, free trade areas play as stumbling role towards global free trade; and when the degree of cost asymmetry is high, multilateral trade system is an equilibrium only if countries choose to form FTAs.

This paper is organized as follows. In section 2, the economic environment is described and the model is set up. Section 3 analyzes the equilibrium and figures out each country's utility under four cases. Section 4 specifies the model by investigating the symmetric endowment case and section 5 discusses the asymmetric endowment case. In section 6, conclusion remarks are made. 


\section{The Model}

Consider a modified version of the partial equilibrium framework developed by Saggi and Yildiz (2011). There are three countries: A, B and C and three goods: $\mathrm{a}, \mathrm{b}$ and $\mathrm{c}$. Good a and b are two non-numeraire goods and $\mathrm{c}$ is a numeraire good. Each country is endowed with only two goods: country $\mathrm{A}$ has $E_{b}^{A}$ units of goods $\mathrm{b}$ and $E_{c}^{A}$ units of goods c; country B has $E_{a}^{B}$ units of good a and $E_{c}^{B}$ units of good c; and country C is endowed with $E_{a}^{C}$ units of good a and $E_{b}^{C}$ units of goods b. In terms of trade, each country imports the good with which it is not endowed and exports at least one of its endowment goods.

These 3 countries have identical utility function given by

$$
U^{i}=\left(C_{a}^{i}\right)^{\alpha}\left(C_{b}^{i}\right)^{\beta}\left(C_{c}^{i}\right)^{1-\alpha-\beta}
$$

where $i=A, B$ and C. $U^{i}$ is the utility level of country $i$ and $C_{j}^{i}$ is its consumption of $\operatorname{good} j, j=a, b$ and c. $\alpha, \beta<0$ and $\alpha+\beta<1$.

Denote the income level of country $i$ by $I^{i}$. With Cobb-Douglas utility function, it is optimal for the consumers to spend their income according to:

$$
\begin{gathered}
C_{a}^{i}=\frac{\alpha I^{i}}{p_{a}^{i}} \\
C_{b}^{i}=\frac{\beta I^{i}}{p_{b}^{i}} \\
C_{c}^{i}=\frac{(1-\alpha-\beta) I^{i}}{p_{c}^{i}}
\end{gathered}
$$

The income level is equal to:

$$
I^{i}=p_{a}^{i} C_{a}^{i}+p_{b}^{i} C_{b}^{i}+p_{c}^{i} C_{c}^{i}
$$

The equilibrium conditions for the three goods are

Since we assume that goods $\mathrm{c}$ is a numeraire good, $P_{c}^{i}=1$. Substitute (2) into (4), these three equations in (4) contain only two independent equations, which can be solved for the two relative prices $P_{a}^{i}$ and $P_{b}^{i}$ when the tariff rates are given.

We consider four situations:

$$
\begin{aligned}
& C_{a}^{A}+C_{a}^{B}+C_{a}^{C}=E_{a}^{B}+E_{a}^{C} \\
& C_{b}^{A}+C_{b}^{B}+C_{b}^{C}=E_{b}^{A}+E_{b}^{C} \\
& C_{c}^{A}+C_{c}^{B}+C_{c}^{C}=E_{c}^{A}+E_{c}^{B}
\end{aligned}
$$

- "f" - global free trade, with all countries removing their tariff restrictions.

- "0" - status quo situation without trade liberalization. Country $i$ imposes a positive ad valorem tariff rate $t^{i}>0$ on imported goods.

- "1" - bilateral trade liberalization. In this case, country A and B form a free trade area and remove the tariffs imposed on the goods imported from each other. However, they maintain their initial tariff rates on country $\mathrm{C}$ and country $\mathrm{C}$ also keeps its initial tariff rate. We do not allow country $\mathrm{A}$ and $\mathrm{B}$ to adjust their external tariff after the formation of FTA between them. This is consistent with what we observe in reality: countries keep their external tariff rates unchanged on the third party after they establish a FTA.

- "1" - bilateral trade liberalization. In this case, country A and C form a free trade area and leave country B isolated.

The objective of this model is to consider various cases regarding trade liberalization available to WTO members today. With the rapid growth of RTA, case " 1 " has been made possible under GATT Article XXIV. We compare the welfare levels of the countries in case " 1 " with those in case " $\mathrm{f}$ ". In particular, we are interested in the conditions under which FTA is a "stumbling bloc" or a "building bloc" towards the world trading system.

\section{Analysis of Four Cases}

Let's consider these four cases. For each situation, we need to derive the competitive price level for each good, the income level and the utility (social welfare) for each country. 


\subsection{Global Free Trade (situation "f”)}

We first analyze the global free trade equilibrium. Use superscript "f" to represent the equilibrium value of a variable under free trade; e.g., $p_{j}^{f}$ is the free trade equilibrium price of good $j$ in all countries. Choosing good c as the numeriare, $p_{c}^{f}=1$. With free trade, the income level of each country is equal to the value of its endowment, i.e.,

$$
\begin{gathered}
I^{A f}=p_{b}^{f} E_{b}^{A}+E_{c}^{A} \\
I^{B f}=p_{a}^{f} E_{a}^{B}+E_{c}^{B} \\
I^{C f}=p_{a}^{f} E_{a}^{C}+p_{b}^{f} E_{b}^{C}
\end{gathered}
$$

Substitute the income levels into equations (2), the good market equilibrium conditions (4a) and (4b) reduce to

$$
\begin{gathered}
(1-\alpha) E_{a}^{W} p_{a}^{f}-\alpha E_{b}^{W} p_{b}^{f}=\alpha E_{c}^{W} \\
-\beta E_{a}^{W} p_{a}^{f}+(1-\beta) E_{b}^{W} p_{b}^{f}=\beta E_{c}^{W}
\end{gathered}
$$

Where $E_{a}^{W}=E_{a}^{B}+E_{a}^{C}, E_{b}^{W}=E_{b}^{A}+E_{b}^{C}$ and $E_{c}^{W}=E_{c}^{A}+E_{c}^{B}$. As explained earlier, condition (4c) is redundant. In matrix form, the above linear equations can be rewritten as:

$$
\left[\begin{array}{cc}
(1-\alpha) E_{a}^{W} & -\alpha E_{b}^{W} \\
-\beta E_{a}^{W} & (1-\beta) E_{b}^{W}
\end{array}\right]\left[\begin{array}{c}
p_{a}^{f} \\
p_{b}^{f}
\end{array}\right]=\left[\begin{array}{c}
\alpha E_{c}^{W} \\
\beta E_{c}^{W}
\end{array}\right]
$$

Then, the two equilibrium relative prices can be solved by using Cramer's rule:

$$
\begin{aligned}
& p_{a}^{f *}=\frac{\alpha E_{c}^{W}}{\gamma E_{a}^{W}} \\
& p_{b}^{f *}=\frac{\beta E_{c}^{W}}{\gamma E_{b}^{W}}
\end{aligned}
$$

and $\gamma=1-\alpha-\beta$. Once the equilibrium prices are obtained, the income level of each country can be computed by using (5). The consumption on each good are derived from (2), the simple form of the demand for each goods are:

$$
\begin{aligned}
C_{j}^{A} & =E_{j}^{w}\left(\frac{\beta E_{b}^{A}}{E_{b}^{w}}+\frac{\gamma E_{c}^{A}}{E_{c}^{w}}\right) \\
C_{j}^{B} & =E_{j}^{w}\left(\frac{\alpha E_{a}^{B}}{E_{a}^{w}}+\frac{\gamma E_{c}^{B}}{E_{c}^{w}}\right) \\
C_{j}^{C} & =E_{j}^{w}\left(\frac{\alpha E_{a}^{C}}{E_{a}^{w}}+\frac{\beta E_{b}^{C}}{E_{b}^{w}}\right)
\end{aligned}
$$

Then the utility of each country under free trade can be evaluated using (1). At equilibrium:

$$
\begin{aligned}
U^{A} & =\left(E_{a}^{w}\right)^{\alpha}\left(E_{b}^{w}\right)^{\beta}\left(E_{c}^{w}\right)^{\gamma}\left(\frac{\beta E_{b}^{A}}{E_{b}^{w}}+\frac{\gamma E_{c}^{A}}{E_{c}^{w}}\right) \\
U^{B} & =\left(E_{a}^{w}\right)^{\alpha}\left(E_{b}^{w}\right)^{\beta}\left(E_{c}^{w}\right)^{\gamma}\left(\frac{\alpha E_{a}^{B}}{E_{a}^{w}}+\frac{\gamma E_{c}^{B}}{E_{c}^{w}}\right) \\
U^{C} & =\left(E_{a}^{w}\right)^{\alpha}\left(E_{b}^{w}\right)^{\beta}\left(E_{c}^{w}\right)^{\gamma}\left(\frac{\alpha E_{a}^{C}}{E_{a}^{w}}+\frac{\beta E_{b}^{C}}{E_{b}^{w}}\right)
\end{aligned}
$$

\subsection{Status Quo (Situation “0”)}

Consider the status quo equilibrium. All countries impose positive, non-prohibitive tariffs on the imported goods from other countries. Denote the tariff rate imposed by country $i$ by $t^{i}>0, i=A, B, C$. Denote the domestic price of good $j$ in country $i$ by $p_{j}^{i}$ and the international price of $\operatorname{good} j$ by $p_{j}^{0}$. With good c as the numeraire good, its international price is 1 , i.e. $p_{c}^{0}=1$. As explained earlier, if these countries have symmetric endowments, then under free trade each country will import the good with which the country is not endowed and will export the other two goods. We assume that the endowments of the countries are close to symmetric so that with the tariffs these countries have patterns of trade the same as that in the symmetric case under free trade. In other 
words, country A $(\mathrm{B}, \mathrm{C})$ imports good a $(\mathrm{b}, \mathrm{c})$ before any FTA is formed. Thus domestic prices in different countries are related to the international prices:

$$
\begin{gathered}
p_{a}^{A}=p_{a}^{0}\left(1+t^{A}\right), p_{b}^{A}=p_{b}^{0}, p_{c}^{A}=1 \\
P_{a}^{B}=p_{a}^{0}, p_{b}^{B}=p_{b}^{0}\left(1+t^{B}\right), p_{c}^{B}=p_{c}^{0} \\
p_{a}^{C}=p_{a}^{0}, p_{b}^{C}=p_{b}^{0}, p_{c}^{C}=1+t^{C}
\end{gathered}
$$

We now examine how the equilibrium prices are determined. Firstly consider country A. Its national income is given by

$$
I^{A 0}=p_{b}^{0} E_{b}^{A}+E_{c}^{A}+t^{A} p_{a}^{0} C_{a}^{A 0}
$$

Substitute this national income function into (2a) to give

$$
C_{a}^{A 0}=\frac{\alpha\left(p_{b}^{0} E_{b}^{A}+E_{c}^{A}\right)}{\lambda^{A} p_{a}^{0}}
$$

where $\lambda^{A}=1+t^{A}-\alpha t^{A}$. Substitute (8) into the national income, yielding

$$
I^{A 0}=\frac{\left(1+t^{A}\right)\left(p_{b}^{0} E_{b}^{A}+E_{c}^{A}\right)}{\lambda^{A}}
$$

Making use of conditions (2) and (9), the consumption demand for all goods in country A are as follows:

$$
\begin{gathered}
C_{a}^{A 0}=\frac{\alpha\left(p_{b}^{0} E_{b}^{A}+E_{c}^{A}\right)}{\lambda^{A} p_{a}^{0}} \\
C_{b}^{A 0}=\frac{\beta\left(1+t^{A}\right)\left(p_{b}^{0} E_{b}^{A}+E_{c}^{A}\right)}{\lambda^{A} p_{b}^{0}} \\
C_{c}^{A 0}=\frac{\gamma\left(1+t^{A}\right)\left(p_{b}^{0} E_{b}^{A}+E_{c}^{A}\right)}{\lambda^{A}}
\end{gathered}
$$

Using the similar approach, the national income functions and the consumption function of the other two countries are

$$
\begin{gathered}
I^{B 0}=\frac{\left(1+t^{B}\right)\left(p_{a}^{0} E_{a}^{B}+E_{c}^{B}\right)}{\lambda^{B}} \\
I^{C 0}=\frac{\left(1+t^{C}\right)\left(p_{a}^{0} E_{a}^{C}+p_{b}^{0} E_{b}^{C}\right)}{\lambda^{C}}
\end{gathered}
$$

where $\lambda^{B}=1+t^{B}-\beta t^{B}$, and $\lambda^{C}=1+t^{C}-(1-\alpha-\beta) t^{C}$. Making use of income function, the consumption demands for country $\mathrm{B}$ and $\mathrm{C}$ are

$$
\begin{gathered}
C_{a}^{B 0}=\frac{\alpha\left(1+t^{B}\right)\left(p_{a}^{0} E_{a}^{B}+E_{c}^{B}\right)}{\lambda^{B} p_{a}^{0}} \\
C_{b}^{B 0}=\frac{\beta\left(p_{a}^{0} E_{a}^{B}+E_{c}^{B}\right)}{\lambda^{B} p_{b}^{0}} \\
C_{c}^{B 0}=\frac{\gamma\left(1+t^{B}\right)\left(p_{a}^{0} E_{a}^{B}+E_{c}^{B}\right)}{\lambda^{B}} \\
C_{a}^{C 0}=\frac{\alpha\left(1+t^{C}\right)\left(p_{a}^{0} E_{a}^{C}+p_{b}^{0} E_{b}^{C}\right)}{\lambda^{C} p_{a}^{0}} \\
C_{b}^{C 0}=\frac{\beta\left(1+t^{C}\right)\left(p_{a}^{0} E_{a}^{C}+p_{b}^{0} E_{b}^{C}\right)}{\lambda^{C} p_{b}^{0}} \\
C_{c}^{C 0}=\frac{\gamma\left(p_{a}^{0} E_{a}^{C}+p_{b}^{0} E_{b}^{C}\right)}{\lambda^{C}}
\end{gathered}
$$


Using market clear condition (4), substitute all consumption function into it, the price of good a and b can be derived through the following linear equation system:

$$
\left[\begin{array}{ll}
A_{1} & A_{2} \\
A_{3} & A_{4}
\end{array}\right]\left[\begin{array}{c}
p_{a}^{0} \\
p_{b}^{0}
\end{array}\right]=\begin{gathered}
A_{5} \\
A_{6}
\end{gathered}
$$

where

$$
\begin{aligned}
& A_{1}=\lambda^{A} \lambda^{C}\left(\lambda^{B}-\alpha \tau^{B}\right) E_{a}^{B}+\lambda^{A} \lambda^{B}\left(\lambda^{C}-\alpha \tau^{C}\right) E_{a}^{C} \\
& A_{2}=-\alpha \lambda^{B} \lambda^{C} E_{b}^{A}-\alpha \lambda^{A} \lambda^{B} \tau^{C} E_{b}^{C} \\
& A_{3}=-\beta \lambda^{A} \lambda^{C} E_{a}^{B}-\beta \lambda^{A} \lambda^{B} \tau^{C} E_{a}^{C} \\
& A_{4}=\lambda^{B} \lambda^{C}\left(\lambda^{A}-\beta \tau^{A}\right) E_{b}^{A}+\lambda^{A} \lambda^{B}\left(\lambda^{C}-\beta \tau^{C}\right) E_{b}^{C} \\
& A_{5}=\alpha \lambda^{B} \lambda^{C} E_{c}^{A}+\alpha \lambda^{A} \lambda^{C} \tau^{B} E_{c}^{B} \\
& A_{6}=\beta \lambda^{B} \lambda^{C} \tau^{A} E_{c}^{A}+\beta \lambda^{A} \lambda^{C} E_{c}^{B}
\end{aligned}
$$

and $\tau^{i}=1+t^{i}$, where $i=A, B$ and $\mathrm{C}$. Equation (16) are solved for the equilibrium international prices:

$$
\begin{gathered}
p_{a}^{0 *}=\frac{A_{4} A_{5}-A_{2} A_{6}}{A_{1} A_{4}-A_{2} A_{3}} \\
p_{b}^{0 *}=\frac{A_{1} A_{6}-A_{3} A_{5}}{A_{1} A_{4}-A_{2} A_{3}}
\end{gathered}
$$

\subsection{Country A-B FTA (Situation "1")}

In this situation, country A and B form a free trade area. Then they remove the tariff restriction on the goods imported from each other. We assume that the tariffs on the goods between country A and C, country B and country $\mathrm{C}$ remain unchanged. We also assume that the trade patterns of the countries are the same as those in the symmetric case, with country A (B, C) importing good a (b, c).

The FTA means that each member country receives a preferential trade treatment from the other member country. For example, when entering country A, the good from country B is not subject to any tariff while the one from country C is. As a result, to import good a, country A will prefer to import it from country B rather than country $\mathrm{C}$, given that both countries offer the good at the same price. The increase in demand will bid up the price of good a in country B but the drop in demand will cause a decrease in its price in country C. In equilibrium, if country A imports good a from country B and C, the price of good a in country B must be higher than the price in country $\mathrm{C}$ and the difference must be equal to the per unit tariff rate imposed by country A. Denote the price of good a in country $\mathrm{C}$ by $p_{a}^{1}$. The equilibrium price of good a in country A and B is $p_{a}^{1}\left(1+t^{A}\right)$. Similarly, denote the price of good $\mathrm{b}$ in country $\mathrm{C}$ by $p_{b}^{1}$, with the corresponding prices in country $\mathrm{A}$ and $\mathrm{B}$ equal to $p_{b}^{1}\left(1+t^{B}\right)$. For country C, no preferential trade is offered. So denote the price of good c in country A and B by $p_{c}^{1}$, and price in country $\mathrm{C}$ will be $p_{c}^{1}\left(1+t^{c}\right)$. Choose good $\mathrm{c}$ as the numeraire so that $p_{c}^{1}=1$.

The tariff revenue of country A is generated from its import from country C. So we have to determine the import volume from country $\mathrm{C}$. To determine the volume, note that consumption for good a in country $\mathrm{C}$ is, from (14a)

$$
C_{a}^{C 1}=\frac{\alpha\left(1+t^{C}\right)\left(p_{a}^{1} E_{a}^{C}+p_{b}^{1} E_{b}^{C}\right)}{\lambda^{C} p_{a}^{1}}
$$

Thus country C's export of good a to country A is equal to

$$
M_{a}^{A C 1}=E_{a}^{C}-C_{a}^{C 1}=\frac{\left(1-\alpha+\beta t^{C}\right) E_{a}^{C} p_{a}^{1}-\alpha\left(1+t^{C}\right) E_{b}^{C} p_{b}^{1}}{\lambda^{C} p_{a}^{1}}
$$

Using the import level in (18), the income level of country $A$ is equal to

$$
\begin{aligned}
I^{A 1} & =E_{c}^{A}+p_{b}^{1}\left(1+t^{B}\right) E_{b}^{A}+t^{A} p_{a}^{1} M_{a}^{A C 1} \\
& =\frac{\lambda^{C} E_{c}^{A}+t^{A}\left(1-\alpha+\beta t^{C}\right) E_{a}^{C} p_{a}^{1}+\left(\lambda^{C}\left(1+t^{B}\right) E_{b}^{A}-\alpha\left(1+t^{C}\right) t^{A} E_{b}^{C}\right) p_{b}^{1}}{\lambda^{C}}
\end{aligned}
$$

Condition (19) gives the consumption demands:

$$
C_{a}^{A 1}=\alpha \frac{\lambda^{C} E_{c}^{A}+t^{A}\left(1-\alpha+\beta t^{C}\right) E_{a}^{C} p_{a}^{1}+\left(\lambda^{C} \tau^{B} E_{b}^{A}-\alpha \tau^{C} t^{A} E_{b}^{C}\right) p_{b}^{1}}{\left(1+t^{A}\right) p_{a}^{1} \lambda^{C}}
$$




$$
\begin{gathered}
C_{b}^{A 1}=\beta \frac{\lambda^{C} E_{c}^{A}+t^{A}\left(1-\alpha+\beta t^{C}\right) E_{a}^{C} p_{a}^{1}+\left(\lambda^{C} \tau^{B} E_{b}^{A}-\alpha \tau^{C} t^{A} E_{b}^{C}\right) p_{b}^{1}}{\left(1+t^{B}\right) p_{b}^{1} \lambda^{C}} \\
C_{c}^{A 1}=\gamma \frac{\lambda^{C} E_{c}^{A}+t^{A}\left(1-\alpha+\beta t^{C}\right) E_{a}^{C} p_{a}^{1}+\left(\lambda^{C} \tau^{B} E_{b}^{A}-\alpha \tau^{C} t^{A} E_{b}^{C}\right) p_{b}^{1}}{\lambda^{C}}
\end{gathered}
$$

Similarly, consumption for good b in country C is, from (14b)

$$
C_{b}^{C 1}=\frac{\beta \tau^{C}\left(p_{a}^{1} E_{a}^{C}+p_{b}^{1} E_{b}^{C}\right)}{p_{b}^{1} \lambda^{C}}
$$

Country B's import of good b from country $\mathrm{C}$ is:

$$
M_{b}^{B C 1}=E_{b}^{C}-C_{b}^{C 1}=\frac{\left(1-\beta+\alpha t^{C}\right) E_{b}^{C} p_{b}^{1}-\beta \tau^{C} E_{a}^{C} p_{a}^{1}}{p_{b}^{1} \lambda^{C}}
$$

Condition (21) defines the national income and consumption demands for country B

$$
\begin{gathered}
I^{B 1}=\frac{\lambda^{C} E_{c}^{B}+t^{B}\left(1-\beta+\alpha t^{C}\right) E_{b}^{C} p_{b}+\left(\lambda^{C}\left(1+t^{A}\right) E_{b}^{B}-\beta\left(1+t^{C}\right) t^{B} E_{a}^{C}\right) p_{a}^{1}}{\lambda^{C}} \\
C_{a}^{B 1}=\alpha \frac{\lambda^{C} E_{c}^{B}+\left(\lambda^{C} \tau^{A} E_{a}^{B}-\beta \tau^{C} t^{B} E_{a}^{C}\right) p_{a}^{1}+t^{B}\left(1-\beta+\alpha t^{C}\right) E_{b}^{C} p_{b}^{1}}{\left(1+t^{A}\right) p_{a}^{1} \lambda^{C}} \\
C_{b}^{B 1}=\beta \frac{\lambda^{C} E_{c}^{B}+\left(\lambda^{C} \tau^{A} E_{a}^{B}-\beta \tau^{C} t^{B} E_{a}^{C}\right) p_{a}^{1}+t^{B}\left(1-\beta+\alpha t^{C}\right) E_{b}^{C} p_{b}^{1}}{\left(1+t^{B}\right) p_{b}^{1} \lambda^{C}} \\
C_{c}^{B 1}=\gamma \frac{\lambda^{C} E_{c}^{B}+\left(\lambda^{C} \tau^{A} E_{a}^{B}-\beta \tau^{C} t^{B} E_{a}^{C}\right) p_{a}^{1}+t^{B}\left(1-\beta+\alpha t^{C}\right) E_{b}^{C} p_{b}^{1}}{\lambda^{C}}
\end{gathered}
$$

Then market clearing condition gives us the following linear equation system

$$
\left[\begin{array}{ll}
B_{1} & B_{2} \\
B_{3} & B_{4}
\end{array}\right]\left[\begin{array}{c}
P_{a}^{1} \\
P_{b}^{1}
\end{array}\right]=\left[\begin{array}{l}
B_{5} \\
B_{6}
\end{array}\right]
$$

where

$$
\begin{aligned}
& B_{1}=\left(\frac{\lambda^{C} \tau^{A}}{\alpha}-t^{A}\left(1-\alpha+\beta t^{C}\right)+\beta \tau^{C} t^{B}-\tau^{A} \tau^{C}\right) E_{a}^{C}+\left(\frac{\lambda^{C} \tau^{A}}{\alpha}-\lambda^{C} \tau^{A}\right) E_{a}^{B} \\
& B_{2}=\left[\alpha \tau^{C} t^{A}-t^{B}\left(1-\beta+\alpha t^{C}\right)-\tau^{A} \tau^{C}\right] E_{b}^{C}-\lambda^{C} \tau^{B} E_{b}^{A} \\
& B_{3}=\left[\beta \tau^{C} t^{B}-t^{A}\left(1-\alpha+\beta t^{C}\right)-\tau^{B} \tau^{C}\right] E_{a}^{C}-\lambda^{C} \tau^{A} E_{a}^{B} \\
& B_{4}=\left(\frac{\lambda^{C} \tau^{B}}{\beta}-t^{B}\left(1-\beta+\alpha t^{C}\right)+\alpha \tau^{C} t^{A}-\tau^{B} \tau^{C}\right) E_{b}^{C}+\left(\frac{\lambda^{C} \tau^{B}}{\beta}-\lambda^{C} \tau^{B}\right) E_{b}^{A} \\
& B_{5}=\lambda^{C} E_{c}^{W} \\
& B_{6}=\lambda^{C} E_{c}^{W}
\end{aligned}
$$

Equation (24) are solved for the equilibrium international prices:

$$
\begin{gathered}
p_{a}^{1 *}=\frac{B_{4} B_{5}-B_{2} B_{6}}{B_{1} B_{4}-B_{2} B_{3}} \\
p_{b}^{1 *}=\frac{B_{1} B_{6}-B_{3} B_{5}}{B_{1} B_{4}-B_{2} B_{3}}
\end{gathered}
$$

\subsection{Country A-C FTA (Situation “1”)}

In the last situation, A-B FTA has been discussed. However, there is another way to form a FTA, that is A-C FTA. In this situation, country $\mathrm{A}$ and $\mathrm{C}$ form a free trade area. Then they remove the tariff restriction on the goods imported from each other. We assume that the tariffs on the goods between country A and B, country $\mathrm{C}$ and country $\mathrm{B}$ remain unchanged. We also assume that the trade patterns of the countries are the same as those in the symmetric case, with country A (B, C) importing good a (b, c).

The FTA means that each member country receives a preferential trade treatment from the other member country. 
For example, when entering country A, the good from country $\mathrm{C}$ is not subject to any tariff while the one from country B is. As a result, to import good a, country A will prefer to import it from country C rather than country $\mathrm{B}$, given that both countries offer the good at the same price. The increase in demand will bid up the price of good a in country $\mathrm{C}$ but the drop in demand will cause a decrease in its price in country B. In equilibrium, if country A imports good a from country B and C, the price of good a in country $\mathrm{C}$ must be higher than the price in country B and the difference must be equal to the per unit tariff rate imposed by country A. Denote the price of good a in country B by $p_{a}^{1}$. The equilibrium price of good a in countries A and C is $p_{a}^{1}\left(1+t^{A}\right)$. Similarly, denote the price of good $\mathrm{c}$ in country $\mathrm{B}$ by $p_{c}^{1}$, with the corresponding prices in country $\mathrm{A}$ and $\mathrm{C}$ equal to $p_{c}^{1}\left(1+t^{c}\right)$. For country B, no preferential trade is offered. So denote the price of good b in country A and C by $p_{b}^{1}$, and price in country B will be $p_{b}^{1}\left(1+t^{B}\right)$. Choose good $\mathrm{c}$ as the numeraire so that $p_{c}^{1}=1$.

The tariff revenue of country A is generated from its import from country B. So we have to determine the import volume from country B. To determine the volume, note that consumption for good a in country B is, from (13a)

$$
C_{a}^{B 1}=\frac{\alpha\left(1+t^{B}\right)\left(p_{a}^{1} E_{a}^{B}+E_{c}^{B}\right)}{\lambda^{B} p_{a}^{1}}
$$

Thus country B's export of good a to country A is equal to

$$
M_{a}^{A B 1}=E_{a}^{B}-C_{a}^{B 1}=\frac{\left(\lambda^{B}-\alpha\left(1+t^{B}\right)\right) p_{a}^{1} E_{a}^{B}-\alpha\left(1+t^{B}\right) E_{c}^{B}}{\lambda^{B} p_{a}^{1}}
$$

Using the import level in (26), the income level of country $A$ is equal to

$$
\begin{aligned}
I^{A 1} & =\left(1+t^{C}\right) E_{c}^{A}+p_{b}^{1} E_{b}^{A}+t^{A} p_{a}^{1} M_{a}^{A B 1} \\
& =\frac{\tau^{C} \lambda^{B} E_{c}^{A}+\lambda^{B} p_{b}^{1} E_{b}^{A}+t^{A}\left(\lambda^{B}-\alpha \tau^{B}\right) p_{a}^{1} E_{a}^{B}-\alpha \tau^{B} t^{A} E_{c}^{B}}{\lambda^{B}}
\end{aligned}
$$

Condition (27) gives the consumption demands:

$$
\begin{gathered}
C_{a}^{A 1}=\alpha \frac{\tau^{C} \lambda^{B} E_{c}^{A}+\lambda^{B} p_{b}^{1} E_{b}^{A}+t^{A}\left(\lambda^{B}-\alpha \tau^{B}\right) p_{a}^{1} E_{a}^{B}-\alpha \tau^{B} t^{A} E_{c}^{B}}{\left(1+t^{A}\right) p_{a}^{1} \lambda^{B}} \\
C_{b}^{A 1}=\beta \frac{\tau^{C} \lambda^{B} E_{c}^{A}+\lambda^{B} p_{b}^{1} E_{b}^{A}+t^{A}\left(\lambda^{B}-\alpha \tau^{B}\right) p_{a}^{1} E_{a}^{B}-\alpha \tau^{B} t^{A} E_{c}^{B}}{p_{b}^{1} \lambda^{B}} \\
C_{c}^{A 1}=\gamma \frac{\tau^{C} \lambda^{B} E_{c}^{A}+\lambda^{B} p_{b}^{1} E_{b}^{A}+t^{A}\left(\lambda^{B}-\alpha \tau^{B}\right) p_{a}^{1} E_{a}^{B}-\alpha \tau^{B} t^{A} E_{c}^{B}}{\left(1+t^{C}\right) \lambda^{B}}
\end{gathered}
$$

Similarly, consumption for good $\mathrm{c}$ in country B is, from (13c)

$$
C_{c}^{B 1}=\frac{\gamma\left(1+t^{B}\right)\left(p_{a}^{1} E_{a}^{B}+E_{c}^{B}\right)}{\lambda^{B}}
$$

Country C's import of good c from country B is:

$$
M_{c}^{C B 1}=E_{c}^{B}-C_{c}^{B 1}=\frac{\left(\lambda^{B}-\gamma\left(1+t^{B}\right)\right) E_{c}^{B}-\gamma\left(1+t^{B}\right) p_{a}^{1} E_{a}^{B}}{\lambda^{B}}
$$

Condition (29) defines the national income and consumption demands for country $\mathrm{C}$

$$
\begin{gathered}
I^{C 1}=\frac{\lambda^{B} p_{b}^{1} E_{b}^{C}+t^{C}\left(\lambda^{B}-\gamma \tau^{B}\right) E_{c}^{B}+\left(\lambda^{B} \tau^{A} E_{a}^{C}-\gamma \tau^{B} t^{C} E_{a}^{B}\right) p_{a}^{1}}{\lambda^{B}} \\
C_{a}^{C 1}=\alpha \frac{\lambda^{B} p_{b}^{1} E_{b}^{C}+t^{C}\left(\lambda^{B}-\gamma \tau^{B}\right) E_{c}^{B}+\left(\lambda^{B} \tau^{A} E_{a}^{C}-\gamma \tau^{B} t^{C} E_{a}^{B}\right) p_{a}^{1}}{\left(1+t^{A}\right) p_{a}^{1} \lambda^{B}} \\
C_{b}^{C 1}=\beta \frac{\lambda^{B} p_{b}^{1} E_{b}^{C}+t^{C}\left(\lambda^{B}-\gamma \tau^{B}\right) E_{c}^{B}+\left(\lambda^{B} \tau^{A} E_{a}^{C}-\gamma \tau^{B} t^{C} E_{a}^{B}\right) p_{a}^{1}}{p_{b}^{1} \lambda^{B}} \\
C_{c}^{C 1}=\gamma \frac{\lambda^{B} p_{b}^{1} E_{b}^{C}+t^{C}\left(\lambda^{B}-\gamma \tau^{B}\right) E_{c}^{B}+\left(\lambda^{B} \tau^{A} E_{a}^{C}-\gamma \tau^{B} t^{C} E_{a}^{B}\right) p_{a}^{1}}{\left(1+t^{C}\right) \lambda^{B}}
\end{gathered}
$$


In order to differentiate the utility under A-B FTA and A-C FTA, footnotes will be used. So ${ }_{A B} U^{i l}$ stands for the utility of country $i$ under A-B FTA case, and ${ }_{n} U^{i 1}$ stands for the utility of country $i$ under A-C FTA case, where $i=A, B, C$.

\section{Symmetric Endowment Case}

If $G F T^{A B}>S Q^{A B}$, global free trade can be achieved through multilateralism. If $F T A^{A B}>G F T^{A B}$, FTA serves as a "stumbling bloc."

Let's consider the symmetric endowment case. Assume $\alpha=\beta=\gamma=\frac{1}{3}, E_{b}^{A}=E_{c}^{A}=E_{a}^{\beta}=E_{a}^{c}=e$ and so on.

GFT case: In such a situation, $p_{a}^{f^{*}}=p_{b}^{f^{*}}=1, I^{A}=I^{B}=I^{C}=2 e, C_{a}^{A}=C_{b}^{A}=C_{c}^{A}=C_{a}^{B}=C_{b}^{B}=C_{c}^{B}=C_{a}^{C}=C_{b}^{C}=C_{c}^{C}=\frac{2}{3} e$. Each country will export one third of each endowed good to the country which does not have this good, and import one third units of absent good from each of the other two countries. The utility level for each country are also the same, $U^{A}=U^{B}=U^{C}=\frac{2}{3} e$.

SQ case: Since these three countries are symmetric, it's natural for us to consider the symmetric tariff levels. We have $t^{A}=t^{B}=t^{C}=t$. Combined the equal weight in utility function, we have $\lambda^{A}=\lambda^{B}=\lambda^{C}=\lambda$, then the above formula in (16) can be rewritten as,

$$
\begin{aligned}
& A_{1}=A_{4}=\left(2 \lambda^{3}-\frac{2}{3} \lambda^{2}(1+t)\right) e \\
& A_{2}=A_{3}=\left(-\frac{1}{3} \lambda^{2}(2+t)\right) e \\
& A_{5}=A_{6}=\left(\frac{1}{3} \lambda^{2}(2+t)\right) e
\end{aligned}
$$

Then the equilibrium prices are

$$
p_{a}^{0 *}=p_{b}^{0 *}=1
$$

With these equilibrium prices, the consumption of each country can be evaluated using (11) and (14).

$$
\begin{gathered}
C_{a}^{A 0}=\frac{2}{3+2 t} e \\
C_{b}^{A 0}=C_{c}^{A 0}=\frac{2+2 t}{3+2 t} e \\
C_{a}^{B 0}=C_{c}^{B 0}=\frac{2+2 t}{3+2 t} e \\
C_{b}^{B 0}=\frac{2}{3+2 t} e \\
C_{a}^{C 0}=C_{b}^{C 0}=\frac{2+2 t}{3+2 t} e \\
C_{c}^{C 0}=\frac{2}{3+2 t} e
\end{gathered}
$$

Compared to free trade, each country consumes less on the good which it is not endowed with, since the tariff rates are imposed. Each country imports $\frac{e}{3+2 t}$ units of absent good from each country and exports $\frac{e}{3+2 t}$ units of its endowed goods to the other two countries. The utility levels for each country are the same, 


$$
U^{A 0}=U^{B 0}=U^{C 0}=\left(\frac{2+2 t}{3+2 t}\right)^{\frac{2}{3}}\left(\frac{2}{3+2 t}\right)^{\frac{1}{3}} e
$$

In symmetric case, it can be calculated that $G F T^{A B}>S Q^{A B}$, since $\frac{2}{3} e>\left(\frac{2+2 t}{3+2 t}\right)^{\frac{2}{3}}\left(\frac{2}{3+2 t}\right)^{\frac{1}{3}} e$. Thus the global free trade can be achieved through multilateralism. And the higher the tariff rates, the worse the welfare of countries under status quo.

A-B FTA case: formula (24) can be rewritten as

$$
\begin{aligned}
& B_{1}=B_{4}=\left(\frac{7}{3} t^{2}+6 t+4\right) e \\
& B_{2}=B_{3}=\left(-\frac{5}{3} t^{2}-4 t-2\right) e \\
& B_{5}=B_{6}=\left(\frac{4}{3} t+2\right) e
\end{aligned}
$$

The equilibrium prices are $p_{a}^{1 *}=p_{b}^{1 *}=\frac{2 t+3}{t^{2}+3 t+3}$. The consumption for each good can be solved as

$$
\begin{aligned}
C_{a}^{A 1} & =C_{b}^{A 1}=\frac{t+2}{2 t+3} e \\
C_{c}^{A 1} & =\frac{t^{2}+3 t+2}{t^{2}+3 t+3} e \\
C_{a}^{B 1} & =C_{b}^{A 1}=\frac{t+2}{2 t+3} e \\
C_{c}^{B 1} & =\frac{t^{2}+3 t+2}{t^{2}+3 t+3} e \\
C_{a}^{C 1} & =C_{b}^{C 1}=\frac{2(t+1)}{2 t+3} e \\
C_{c}^{C 1} & =\frac{2}{t^{2}+3 t+3} e
\end{aligned}
$$

The the utility level of country A and B are

$$
U^{A 1}=U^{B 1}=\left(\frac{t+2}{2 t+3}\right)^{\frac{2}{3}}\left(\frac{t^{2}+3 t+2}{t^{2}+3 t+3}\right)^{\frac{1}{3}} e
$$

we have $\left(\frac{t+2}{2 t+3}\right)^{\frac{2}{3}}\left(\frac{t^{2}+3 t+2}{t^{2}+3 t+3}\right)^{\frac{1}{3}}>\frac{2}{3}$. Then $F T A^{A B}>G F T^{A B}$, the bilateral FTA is serving as a "stumbling bloc".

A-C FTA case: the equilibrium prices are

$$
\begin{gathered}
p_{a}^{1 *}=1 \\
p_{b}^{1 *}=\frac{t^{2}+3 t+3}{2 t+3}
\end{gathered}
$$

The consumption for each good can be solved as

$$
\begin{aligned}
C_{a}^{A 1} & =C_{c}^{A 1}=\frac{e}{2 t+3}(t+2) \\
C_{b}^{A 1} & =e \frac{t^{2}+3 t+2}{t^{2}+3 t+3} \\
C_{a}^{B 1} & =C_{c}^{B 1}=2 \frac{e}{2 t+3}(t+1) \\
C_{b}^{B 1} & =2 \frac{e}{t^{2}+3 t+3} \\
C_{a}^{C 1} & =C_{c}^{C 1}=\frac{e}{2 t+3}(t+2) \\
C_{b}^{C 1} & =e \frac{t^{2}+3 t+2}{t^{2}+3 t+3}
\end{aligned}
$$


The utility level of each country are as follows

$$
\begin{gathered}
A C U^{A 1}={ }_{A C} U^{C 1}=e\left(\frac{t+2}{2 t+3}\right)^{\frac{2}{3}}\left(\frac{t^{2}+3 t+2}{t^{2}+3 t+3}\right)^{\frac{1}{3}} \\
{ }_{A C} U^{B 1}=2 e\left(\frac{t+1}{2 t+3}\right)^{\frac{2}{3}}\left(\frac{1}{4 t^{2}+12 t+12}\right)^{\frac{1}{3}}
\end{gathered}
$$

For country A, the utility under A-B FTA and A-C FTA are the same. So the FTA is a stumbling bloc not only in A-B FTA case, but also in A-C FTA case.

\section{Asymmetric Endowment Case}

In asymmetric case, FTA may serve as a "stumbling bloc", too. Let's consider an asymmetric case: Assume $\alpha=\beta=\gamma=\frac{1}{3}$, country A and B have same endowment $E_{b}^{A}=E_{c}^{A}=E_{a}^{B}=E_{c}^{B}=e$, and country $\mathrm{C}$ has endowment $E_{a}^{c}=E_{b}^{c}=\theta e$, where $0<\theta<1$. That is to say country A an B are large countries, while country $\mathrm{C}$ is a small one.

GFT case: In such a case, two equilibrium relative prices are $p_{a}^{f *}=\frac{\alpha E_{c}^{W}}{\gamma E_{a}^{W}}=\frac{2}{1+\theta}=p_{b}^{f *}$

Once the equilibrium prices are obtained, the income level of each country can be computed by using (5). The consumption on each good are derived from (2). Then the utility of each country under free trade can be evaluated by using (1). At equilibrium:

$$
\begin{aligned}
U^{A f} & =\left(\frac{1}{1+\theta}\right)^{\frac{1}{3}}\left(\frac{1}{2}\right)^{\frac{2}{3}}\left(\frac{3+\theta}{3}\right) e \\
U^{B f} & =\left(\frac{1}{1+\theta}\right)^{\frac{1}{3}}\left(\frac{1}{2}\right)^{\frac{2}{3}}\left(\frac{3+\theta}{3}\right) e \\
U^{C f} & =\frac{2 \theta}{3}\left(\frac{2}{1+\theta}\right)^{\frac{1}{3}} e
\end{aligned}
$$

When $\theta<1$, the endowment of country $\mathrm{C}$ is less than the other two countries, its equilibrium utility is also less than the utility level of the other two countries.

Status Quo case: We start from a simple case, assume $t^{A}=t^{B}=t^{C}=t$. Combined the equal weight in utility function, we have $\lambda^{A}=\lambda^{B}=\lambda^{c}=\lambda$, then the above formula in (17) can be rewritten as,

$$
\begin{aligned}
& A_{1}=A_{4}=(1+\theta)\left(\lambda^{3}-\frac{1}{3} \lambda^{2}(1+t)\right) e \\
& A_{2}=A_{3}=-\frac{1}{3} \lambda^{2}[1+(1+t) \theta] e \\
& A_{5}=A_{6}=\frac{1}{3} \lambda^{2}(2+t) e
\end{aligned}
$$

Then the equilibrium prices are $p_{a}^{0 *}=p_{b}^{0 *}=\frac{t+2}{t+\theta+1}$

With these equilibrium prices, the consumption of each country can be evaluated using (11) and (14).

$$
\begin{gathered}
C_{a}^{A 0}=C_{a}^{B 0}=e \frac{2 t+\theta+3}{(t+2)(2 t+3)} \\
C_{b}^{A 0}=C_{b}^{B 0}=e \frac{(t+1)(2 t+\theta+3)}{(2 t+3)(t+2)} \\
C_{c}^{A 0}=C_{c}^{B 0}=e \frac{(t+1)(2 t+\theta+3)}{(2 t+3)(t+\theta+1)} \\
C_{a}^{C 0}=C_{b}^{C 0}=\frac{2 \theta(t+1)}{2 t+3} e \\
C_{c}^{C 0}=\frac{(2 t+4) \theta}{(t+\theta+1)(2 t+3)} e
\end{gathered}
$$


Then

$$
\begin{aligned}
U^{A 0}=U^{B 0} & =\left(\frac{2 t+\theta+3}{2 t+3}\right)\left(\frac{t+1}{t+2}\right)^{\frac{2}{3}}\left(\frac{1}{t+\theta+1}\right)^{\frac{1}{3}} e \\
U^{C 0} & =\frac{2}{2 t+3}(t+1)^{\frac{2}{3}}\left(\frac{t+2}{t+\theta+1}\right)^{\frac{1}{3}} \theta e
\end{aligned}
$$

Compare $G F T^{A B}$ and $S Q^{A B}$, when tariff $t$ is not too small, say larger than $10 \%$, we have $G F T^{A B}>S Q^{A B}$. If $t$ is too low, then country A and B has no incentive to pursue global free trade. However, since external tariffs are usually larger than $10 \%$, condition $G F T^{\wedge B}>S Q^{\Lambda B}$ holds.

Compare $G F T^{c}$ and $S Q^{c}$, we only consider the case with $t>0$, when $\theta<1$, i.e., country $\mathrm{C}$ has a smaller endowment, country $\mathrm{C}$ prefers global free trade whatever tariff level in the status quo is since $G F T^{c}-S Q^{c}>0$.

A-B FTA case: In this case, country A and B establish a FTA and leaves country C isolated. In an asymmetric case, the formula (24) can be rewritten as

$$
\begin{gathered}
B_{1}=B_{4}=\frac{1}{3} e\left(10 t+6 \theta+8 t \theta+3 t^{2} \theta+4 t^{2}+6\right) \\
B_{2}=B_{3}=-\frac{1}{3} e\left(5 t+3 \theta+7 t \theta+3 t^{2} \theta+2 t^{2}+3\right) \\
B_{5}=B_{6}=2\left(1+\frac{2}{3} t\right) e
\end{gathered}
$$

And the equilibrium prices are derived as

$$
p_{a}^{1 *}=p_{b}^{1 *}=\frac{4 t+6}{5 t+3 \theta+t \theta+2 t^{2}+3}
$$

The consumption of each goods in country A are

$$
\begin{aligned}
C_{a}^{A 1} & =C_{b}^{A 1}=\frac{(2 t+\theta+3) e}{4 t+6} \\
C_{c}^{A 1} & =\frac{e(t+1)(2 t+\theta+3)}{5 t+3 \theta+t \theta+2 t^{2}+3}
\end{aligned}
$$

Consequently, the utility level of country A can be calculated, since country A and B are symmetric, we have

$$
U^{A 1}=U^{B 1}=(2 t+\theta+3)\left(\frac{1}{4 t+6}\right)^{\frac{2}{3}}\left(\frac{t+1}{5 t+3 \theta+t \theta+2 t^{2}+3}\right)^{\frac{1}{3}} e
$$

Compare $F T A^{A B}$ and $S Q^{A B}, F T A^{A B}$ and $G F T^{A B}$. We have

$$
\begin{gathered}
F T A^{A B}-S Q^{A B}>0 \\
F T A^{A B}-G F T^{A B}>0
\end{gathered}
$$

Compare $F T A^{c}$ and $G F T^{c}$. Let's derive the utility level in country C

$$
\begin{gathered}
C_{a}^{C 1}=C_{b}^{C 1}=\frac{2(t+1)}{2 t+3} \theta e \\
C_{c}^{C 1}=2 e-2 \frac{e(t+1)(2 t+\theta+3)}{5 t+3 \theta+t \theta+2 t^{2}+3}=\frac{4 \theta e}{5 t+3 \theta+t \theta+2 t^{2}+3}
\end{gathered}
$$

Therefore, the utility in country $\mathrm{C}$ is

$$
U^{C 1}=\left(\frac{2 t+2}{2 t+3}\right)^{\frac{2}{3}}\left(\frac{4}{5 t+3 \theta+t \theta+2 t^{2}+3}\right)^{\frac{1}{3}} \theta e
$$

In global free trade, 


$$
U^{C f}=\frac{2 \theta}{3}\left(\frac{2}{1+\theta}\right)^{\frac{1}{3}} e
$$

Take the difference, yielding that

$$
\begin{gathered}
F T A^{C}-G F T^{C}<0 \\
F T A^{C}-S Q^{C}<0
\end{gathered}
$$

In conclusion, we have ${ }_{A B} F T A^{A}>G F T^{A}>S Q^{A},{ }_{A B} F T A^{B}>G F T^{B}>S Q^{B}, G F T^{C}>S Q^{C}>_{A B} F T A^{C}$.

So far, through a series of comparison, we can conclude that: in an asymmetric case, if $t$ is too low, then country A and B has no incentives to pursue global free trade. In this sense, multilateralism is not working. But if we allow for the establishment of bilateral free trade, bilateral free trade may serve as a building bloc towards global free trade. From the above analysis, it is easily seen country A and B would like to form a FTA first. The formation of this FTA put country $\mathrm{C}$ in a worse position since $F T A^{C}<G F T^{C}$. Now if A and B want to include country $\mathrm{C}$ into the free trade area, country $\mathrm{C}$ will agree. However, country A and B don't have incentives to do so, since their utility are lower under GFT: ${ }_{A B} F T A^{A B}>G F T^{A B}$. So in this case, bilateral free trade serve as a stumbling bloc in the end.

A-C FTA case: In this case, country A and C establish a FTA and leaves country B isolated. In an asymmetric case, from the formula (25), (28), (31), we can obtain the consumption of good a and c in each country:

$$
\begin{gathered}
C_{a}^{B 1}=\frac{e}{p_{a}} \frac{p_{a}+1}{2 t+3}(t+1) \\
C_{c}^{B 1}=e \frac{p_{a}+1}{2 t+3}(t+1) \\
C_{a}^{A 1}=\frac{1}{p_{a}(2 t+3)(t+1)}\left(e+e p_{b}+\frac{1}{3} t^{2} e+\frac{4}{3} t e+\frac{2}{3} e t p_{a}+\frac{2}{3} e t p_{b}+\frac{1}{3} e t^{2} p_{a}\right) \\
C_{c}^{A 1}=\frac{1}{(2 t+3)(t+1)}\left(e+e p_{b}+\frac{1}{3} t^{2} e+\frac{4}{3} t e+\frac{2}{3} e t p_{a}+\frac{2}{3} e t p_{b}+\frac{1}{3} e t^{2} p_{a}\right) \\
C_{a}^{C 1}=\frac{1}{3 p_{a}} \frac{e}{(2 t+3)(t+1)}\left(2 t-t p_{a}+3 \theta p_{a}+3 \theta p_{b}-t^{2} p_{a}+t^{2}+5 t \theta p_{a}+2 t \theta p_{b}+2 t^{2} \theta p_{a}\right) \\
C_{c}^{C 1}=\frac{1}{3} \frac{e}{(2 t+3)(t+1)}\left(2 t-t p_{a}+3 \theta p_{a}+3 \theta p_{b}-t^{2} p_{a}+t^{2}+5 t \theta p_{a}+2 t \theta p_{b}+2 t^{2} \theta p_{a}\right)
\end{gathered}
$$

According to the formula (4), the equilibrium prices are derived as

$$
\begin{gathered}
p_{a}^{1 *}=\frac{2}{1+\theta} \\
p_{b}^{1 *}=\frac{1}{(\theta+1)^{2}(2 t+3)}\left(4 t+6 \theta+8 t \theta+3 t^{2} \theta+t^{2}+6\right)
\end{gathered}
$$

The consumption of each country can be obtained by putting the equilibrium prices into formula (25), (28), (31), then the utility level of each country can be calculated:

$$
\begin{gathered}
{ }_{A C} U^{A 1}=e\left(t^{2} \theta^{2}+7 t^{2} \theta+4 t^{2}+4 t \theta^{2}+20 t \theta+12 t+3 \theta^{2}+12 \theta+9\right) H \\
{ }_{A C} U^{B 1}=\frac{1}{2} e(\theta+3)\left(\frac{t+1}{2 t+3}\right)^{\frac{2}{3}}\left(\frac{1}{4 t+6 \theta+8 t \theta+3 t^{2} \theta+t^{2}+6}\right)^{\frac{1}{3}} \\
{ }_{A C} U^{C 1}=e\left(8 t^{2} \theta^{2}+5 t^{2} \theta-t^{2}+20 t \theta^{2}+16 t \theta+12 \theta^{2}+12 \theta\right) H
\end{gathered}
$$

In which

$$
H=\frac{1}{3(\theta+1)}\left(\frac{1}{(2 t+3)(t+1)}\right)^{\frac{2}{3}}\left(\frac{1}{2\left(4 t+6 \theta+8 t \theta+3 t^{2} \theta+t^{2}+6\right)}\right)^{\frac{1}{3}}
$$

After a series of comparisons, we can figure out that

$$
\begin{aligned}
& { }_{A C} F T A^{A}>G F T^{A}>S Q^{A} \\
& G F T^{B}>S Q^{B}>_{A C} F T A^{B}
\end{aligned}
$$




$$
\begin{aligned}
{ }_{A C} F T A^{C} & >G F T^{C}>S Q^{C}, \text { when } 0<t<t^{*} \\
G F T^{C} & >{ }_{A C} F T A^{C}>S Q^{C}, \text { when } t>t^{*}
\end{aligned}
$$

Since A-B FTA and A-C FTA are two ways to form a FTA, and maybe two ways to get GFT eventually, we have to know which way country A would like more, A-B FTA or A-C FTA. So the utility of country A under A-B FTA and A-C FTA should be compared. From the following relation, it is clear that country A will choose C to form a FTA instead of country B.

$$
\begin{aligned}
& { }_{A C} F T A^{A}-{ }_{A B} F T A^{A} \\
& =\left(t^{2} \theta^{2}+7 t^{2} \theta+4 t^{2}+4 t \theta^{2}+20 t \theta+12 t+3 \theta^{2}+12 \theta+9\right) \frac{1}{3(\theta+1)}\left(\frac{1}{(2 t+3)(t+1)}\right)^{\frac{2}{3}} \\
& \left(\frac{1}{2\left(4 t+6 \theta+8 t \theta+3 t^{2} \theta+t^{2}+6\right)}\right)^{\frac{1}{3}}-(2 t+\theta+3)\left(\frac{1}{4 t+6}\right)^{\frac{2}{3}}\left(\frac{t+1}{5 t+3 \theta+t \theta+2 t^{2}+3}\right)^{\frac{1}{3}}>0
\end{aligned}
$$

Based upon the above relations of utility, we can conclude that: country A and B have incentives to form a FTA as ${ }_{A B} F T A^{A B}>S Q^{A B}$, while country $\mathrm{A}$ and $\mathrm{C}$ also have incentive to form a FTA as ${ }_{A C} F T A^{A C}>G F T^{A C}$. However, the utility of country A is higher when it chooses $\mathrm{C}$ to form a FTA than chooses B. So country A will definitely choose $\mathrm{C}$ to form a FTA.

When the tariff rate is not too high, say $0<t<t^{*}$, country A and C form a FTA. Country B has incentive to join the FTA because its utility under GFT is higher than under FTA: $G F T^{B}>{ }_{A C} F T A^{B}$. But country A and C don't want $\mathrm{B}$ to join in since their utility level will be lower under GFT: ${ }_{A C} F T A^{A C}>G F T^{A C}$. In this situation, we say FTA is a stumbling bloc to GFT.

When the tariff is a bit higher, that is $t>t^{*}$, country A and C form a FTA. Again, country B has incentive to join the FTA and Country A doesn't want B to join. However, country $C$ hopes B can join because its utility will be higher under GFT this time: $G F T^{C}>{ }_{A C} F T A^{C}$. But since A is a much bigger country than C, its discursive power has a larger weight in any decision in FTA. So again, country B has no access to the FTA in this situation and FTA is a stumbling bloc to GFT.

\section{Concluding Remarks}

In this paper, I analyze the impact of a free trade area on the incentives for further liberalization. And it shows that free trade area always plays as a stumbling bloc no matter when the three-country model is under symmetric case or asymmetric case.

The results of the asymmetric case in this paper can be summarized as follows. Before forming a FTA, the isolated country's utility would be lower than status quo, that is to say all the three countries have incentives to form a FTA because the isolated one would be put in the worst place. Then we assume, country A is a powerful country. And it will choose country $\mathrm{C}$ to be its free trade partner, because it is more profitable for country A to form a FTA with country C instead of country B. After forming the A-C FTA, country B would like to join in since its utility would be higher under GFT than A-C FTA. However, when the tariff is not too high, as the utility of country A and C would be lower under GFT, they don't want B to join in. When the tariff is high enough, such as tariffs of automobile industry and luxury products, the utility of country A would be lower under GFT and that of country C would be higher, i.e. country A will object GFT while country C will propose. Since country A is a large country with higher discursive power in making decisions, whether tariff is high or low, A-C FTA won't let country B to join them. So FTA plays a detrimental role to multilateral trading system and global free trade.

This result can illustrate some interesting phenomena such as the previously US-led Trans-Pacific Partnership (TPP). TPP, also known as the Trans-Pacific Strategic Economic Partnership Agreement, is a multilateral trading system which aims at promoting further liberalization in the Asian-Pacific region. The United States had a leading role before it's withdrawal from TPP because of its strong economical and political power. So the United States could be seen as the large country A, while the other countries can be seen as the small country C. However, as the world second largest economic entity, China hasn't participated in TPP negotiations. And TPP has been widely considered to aim at and contain China (here can be seen as the large country B). President Obama claimed that there would be friendly and constructive competition between the Unites States and China only if China would like to appreciate CNY to balance trade deficit, respect intellectual property rights and allow American companies to compete equally in China. It is clear that China was not welcomed now by TPP, which can be elaborated by our paper.

As for the asymmetric case, large countries have incentives to form a FTA with a small country. Many large countries in the real world positively seek opportunities to collaborate with small countries. In 2002, China and 
ASEAN Free Trade Area (CAFTA) has been established, becoming one of the three largest Regional Trade Areas in the world. Later, South Korea and Japan signed FTA with ASEAN countries in 2007 and 2008 respectively. While the United States, Canada, and Mexico has renegotiated NAFTA under a new United States-Mexico-Canada Comprehensive Agreement (USMCA) in October 2018. Besides FTAs, China has actively carried out trade activities with Central and Eastern European (CEE) countries under the background of the Belt and Road Initiative. According to Chinese Government Website, the trade volume between China and CEE has increased by $21 \%$ to 82.2 billion USD in 2018 , which attained historic peek levels. For large countries, small countries like ASEAN and CEE are emerging markets with lots of opportunities to explore, while emerging markets would benefit from trade and even FTAs.

This paper also has much space to improve and needs further study. First, I use partial equilibrium framework and Cobb-Douglas utility function is applied to simplify countries' utility into the function of their consumption level. But this way of representing a country's utility is a bit restricted since producers' profit and governments' tariff revenue are eliminated. Second, tariffs and the decisions to join FTA might be endogenous. As a member country may increase its tariff set against non-member countries and lower its tariff against other member countries after entering a FTA, tariff and decisions should be considered as endogenous. Third, we assume that the endowments of the countries are close to symmetric so that with the tariffs these countries have patterns of trade the same as that in the symmetric case under free trade. In other words, country A (B, C) imports good a (b, c) before any FTA is formed. However, when the degree of endowment asymmetry is large, large countries may not import from small country, so the whole model may not hold. Fourth, this paper assumes all the countries have certain endowments instead of producing goods for trade, thus, it ignores the cost of producing goods for trade.

\section{References}

Bagwell, K., \& Staiger, R. (1999). Regionalism and multilateral tariff cooperation. In J. Piggott, \& A. Woodland (Eds.), International Trade Policy and the Pacific Rim. Macmillan, London.

Baldwin, R. E. (2006). Multilateralising regionalism: Spaghetti bowls as building blocs on the path to Global Free Trade. The World Economy, 29, 1451-1518. https://doi.org/10.1111/j.1467-9701.2006.00859.x

Bernhard, H., \& Macro, W. (2011). Regionalism as a building block for multilateralism. Global Economy Journal 11(1), 21-35. https://doi.org/10.2202/1524-5861.1676

Bhagwati, J. N. (1991). The world trading system at risk. Princeton: Princeton University Press.

Cadot, O., Melo, J. D., \& Olarreaga, M. (1999). Regional integration and lobbying for tariffs against non-members. International Economic Review, 40, 635-657. https://doi.org/10.1111/1468-2354.00032

Cheong, J., \& Wong, K. (2010). Global free trade: Regionalism as a building block or a stumbling block? working paper.

Chinese Government Website. (2019). Retrieved November 22, 2019, from http://www.gov.cn/xinwen/2019-04/06/content_5380139.htm

Freund, C. (2000). Multilateralism and the endogenous formation of preferential trade agreements. Journal of International Economics, 52, 359-376. https://doi.org/10.1016/S0022-1996(99)00051-3

Krishna, P. (1998). Regionalism and multilateralism: A political economy approach. Quarterly Journal of Economics, 113, 227-252. https://doi.org/10.1162/00335539851144162

Levy, P. (1997). A political-economic analysis of free-trade agreements. American Economic Review, 87, 506-519. Retrieved from www.jstor.org/stable/2951361

McLaren, J. (2002). A theory of insidious regionalism. Quarterly Journal of Economics, 117, 571-608. https://doi.org/10.1162/003355302753650337

Ornelas, E. (2005). Endogenous free trade agreements and the multilateral trading system. Journal of International Economics, 67 (2005), 471-491. https://doi.org/10.1016/j.jinteco.2004.11.004

Ornelas, E. (2005). Trade creating free trade areas and the undermining of multilateralism. European Economic Review, 49(2005), 1717-1735. https://doi.org/10.1016/j.euroecorev.2004.03.010

Panagariya, A., \& Findlay, R. (1996). A political-economy anaysis of free-trade areas and customs unions. In R. Feenstra, G. Grossman, \& D. Irwin (Eds.), The Political Economy of Trade Reform: Essays in Honor of J. Bhagwati. MIT Press, Cambridge, MA.

Riezman, R. (1999). Can bilateral trade agreements help to induce free-trade? Canadian Journal of Economics, 
32, 751-766. https://doi.org/10.2307/136448

Saggi, K., Yildiz, H. M. (2011). Bilateral trade agreements and the feasibility of multilateral free trade. Review of International Economics, 19(2), 356-373. https://doi.org/10.1111/j.1467-9396.2011.00952.x

World Trade Organization. (2019). Regional Trade Agreements Database. Retrieved November 22, 2019, from http://rtais.wto.org/UI/PublicMaintainRTAHome.aspx

Yi, S. (2000). Free-trade areas and welfare: An equilibrium analysis. Review of International Economics, 8, 336-347. https://doi.org/10.1111/1467-9396.00225

\section{Appendix A}

\section{Comparison under symmetric case}

1. $G F T^{A B}$ and $\mathrm{SQ}^{A B}$

In symmetric case, it can be calculated that $G F T^{\lambda B}>S Q^{A B}$, since $\frac{2}{3} e>\left(\frac{2+2 t}{3+2 t}\right)^{\frac{2}{3}}\left(\frac{2}{3+2 t}\right)^{\frac{1}{3}}$. Thus the global free trade can be achieved through multilateralism. In particular, The difference between them can be illustrated in Figure 1 when $e=1$.

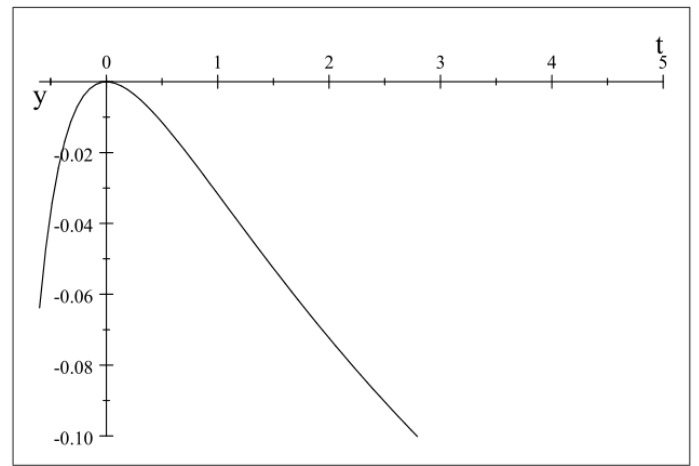

Figure 1. Difference between $\mathrm{SQ}^{\mathrm{AB}}$ and $\mathrm{GFT}^{\mathrm{AB}}$

So the higher the tariff rates, the worse the welfare of countries under status quo.

2. $F T A^{A B}$ and $G F T^{A B}$

$F T A^{A B}-G F T^{A B}=\left(\frac{t+2}{2 t+3}\right)^{\frac{2}{3}}\left(\frac{t^{2}+3 t+2}{t^{2}+3 t+3}\right)^{\frac{1}{3}} e-\frac{2}{3} e$. When $e=1$, the difference between them can be illustrated in Figure 2 .

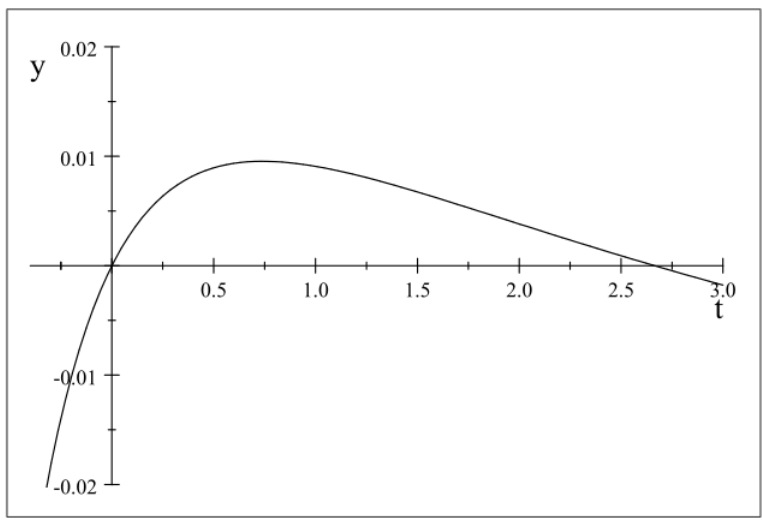

Figure 2. Difference between $F T A^{\wedge B}$ and $G F T^{\wedge B}$

So we have $\left(\frac{t+2}{2 t+3}\right)^{\frac{2}{3}}\left(\frac{t^{2}+3 t+2}{t^{2}+3 t+3}\right)^{\frac{1}{3}}>\frac{2}{3}$ when $t<270 \%$. Then $F T A^{A B}>G F T^{\wedge B}$, the bilateral FTA is serving as a "stumbling bloc". 


\section{Appendix B}

\section{Comparison under asymmetric case}

1. $G F T^{\wedge B}$ and $S Q^{A B}$.

In asymmetric case, when $\mathrm{e}=1$,

$G F T^{A B}-S Q^{A B}=\left(\frac{1}{1+\theta}\right)^{\frac{1}{3}}\left(\frac{1}{2}\right)^{\frac{2}{3}}\left(\frac{3+\theta}{3}\right)-\left(\frac{1}{t+\theta+1}\right)^{\frac{1}{3}}\left(\frac{t+1}{t+2}\right)^{\frac{2}{3}}\left(\frac{2 t+\theta+3}{2 t+3}\right)$.

If $\theta=0.5$, the difference can be graphed as Figure 3 .

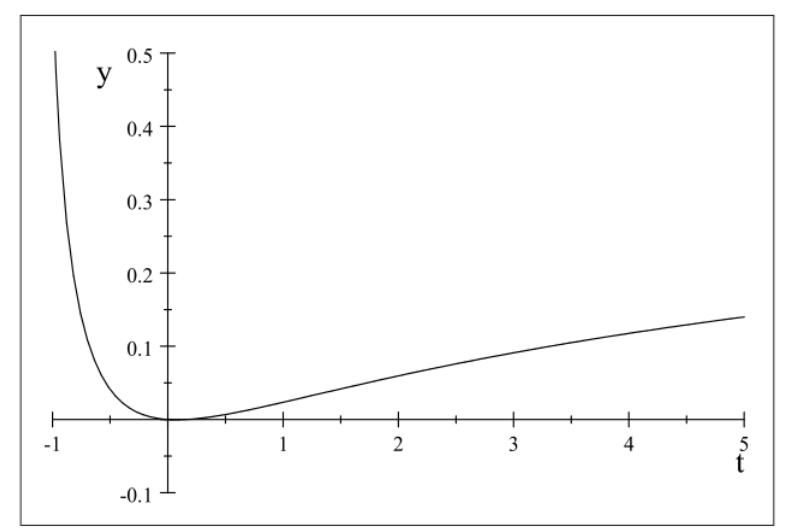

Figure 3. Difference between $G F T^{\star B}$ and $S Q^{a B}$

After calculation, we find that when $\mathrm{t}>t_{1}, G F T^{A B}-\mathrm{SQ}^{A B}>0$, where $10 \%<t_{1}<20 \%$. If the degree of endowment asymmetry is small, for example, $\theta=0.9$, it is found that when $\mathrm{t}>t_{2}, G F T^{A B}-\mathrm{SQ}^{A B}>0$, where $4 \%<t_{2}<5 \%$. And if $\theta=0.8$, it is found that when $\mathrm{t}>t_{3}, G F T^{A B}-\mathrm{SQ}^{A B}>0$, where $7 \%<t_{3}<8 \%$. As we have assumed that the endowments of the countries are close to symmetric so that with the tariffs these countries have patterns of trade the same as that in the symmetric case under free trade, $\theta$ cannot be too small, otherwise the whole model might not holds. And according to the external tariffs statistics, tariffs are usually over $10 \%$, so $G F T^{A B}-\mathrm{SQ}^{A B}>0$ will hold.

2. $G F T^{c}$ and $S Q^{c}$

Compare $G F T^{c}$ and $S Q^{c}$, we have the Figure 4 .

$G F T^{C}-S Q^{C}=0 \Rightarrow \frac{2 \theta}{3}\left(\frac{2}{1+\theta}\right)^{\frac{1}{3}}-\frac{2 \theta}{2 t+3}\left(\frac{t+2}{t+\theta+1}\right)^{\frac{1}{3}}(t+1)^{\frac{2}{3}}=0 \Rightarrow \theta=\frac{t}{\left(\frac{3}{2 t+3}\right)^{3}(t+1)^{2} \frac{t+2}{2}-1}-1$

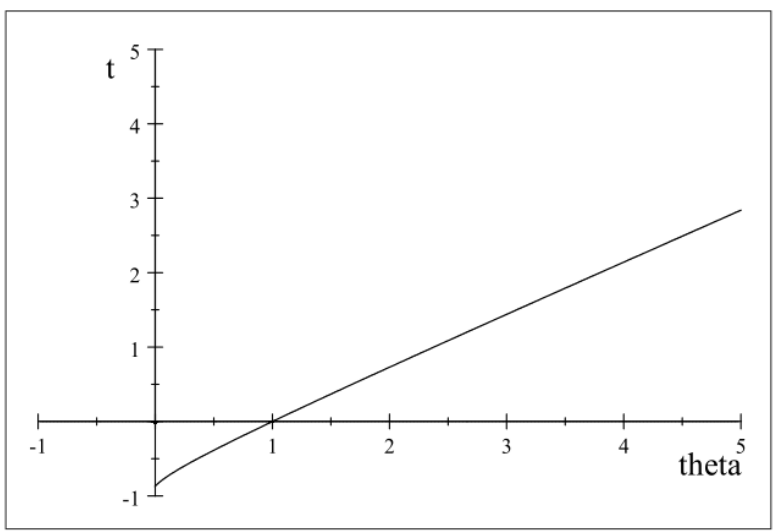

Figure 4. Difference between $G F T^{c}$ and $S Q^{c}$

In the area above the curve, $G F T^{C}-\mathrm{SQ}^{C}>0$, country $\mathrm{C}$ prefers global free trade. In the area below the curve, $G F T^{C}-\mathrm{SQ}^{C}<0$, country $\mathrm{C}$ prefers status quo equilibrium utility. We only consider the case with $t>0$, when $\theta<1$, i.e., country $\mathrm{C}$ has a smaller endowment, country $\mathrm{C}$ prefers global free trade whatever tariff level in the status quo is. 
3. ${ }_{A B} F T A^{A B}$ and $S Q^{A B}$

Compare ${ }_{A B} F T A^{A B}$ and $S Q^{A B}$, we have figure 5 .

$$
\begin{aligned}
& { }_{A B} F T A^{A B}-S Q^{A B}=0 \\
& \Rightarrow\left(\frac{(t+1)(2 t+3)}{(t+1)(2 t+3)+(t+3) \theta}\right)^{\frac{1}{3}}\left(\frac{1}{2}\right)^{\frac{2}{3}}\left(\frac{2 t+\theta+3}{2 t+3}\right) e-\left(\frac{1}{t+\theta+1}\right)^{\frac{1}{3}}\left(\frac{t+1}{t+2}\right)^{\frac{2}{3}}\left(\frac{2 t+\theta+3}{2 t+3}\right) e=0 \\
& \Rightarrow \theta=\left(1-\frac{(t+2)^{2}}{4(t+1)}\right)\left(\left(\frac{t+2}{2 t+2}\right)^{2}-\frac{t+3}{(t+2)(2 t+3)}\right)^{-1}
\end{aligned}
$$

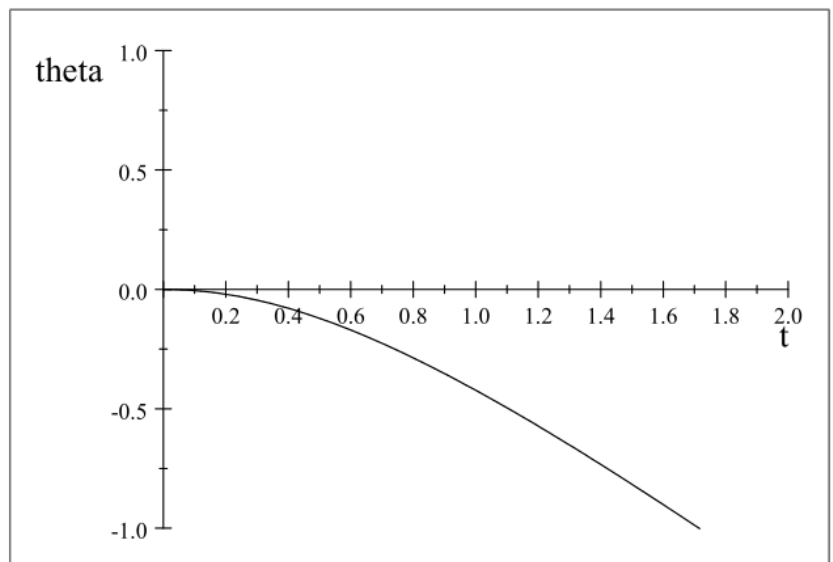

Figure 5. Difference between ${ }_{{ }_{B}} F T A^{A B}$ and $S Q^{A B}$

In the area above the curve in Figure 5, ${ }_{A B} F T A^{A B}-S Q^{A B}>0$, country A and B prefer to form a FTA. In the area below the curve, ${ }_{A B} F T A^{A B}-S Q^{A B}<0$, country $\mathrm{A}$ and $\mathrm{B}$ prefer status quo equilibrium utility. We only consider the case with $t>0$, when $\theta<1$, i.e., country $\mathrm{C}$ has a smaller endowment, country A and B prefer to form a FTA whatever tariff level in the status quo is.

4. ${ }_{A B} F T A^{A B}$ and $G F T^{A B}$

Compare ${ }_{A B} F T A^{A B}$ and $G F T^{A B}$, we have

$$
\begin{aligned}
& A B F T A^{A B}-G F T^{A B} \\
& =(2 t+\theta+3)\left(\frac{1}{2 t+3}\right)^{\frac{2}{3}}\left(\frac{t+1}{(t+1)(2 t+3)+(t+3) \theta}\right)^{\frac{1}{3}}\left(\frac{1}{2}\right)^{\frac{2}{3}} e-\left(\frac{1}{(1+\theta)}\right)^{\frac{1}{3}}\left(\frac{3+\theta}{3}\right)\left(\frac{1}{2}\right)^{\frac{2}{3}} e
\end{aligned}
$$

If $\theta=0.5$, the difference can be graphed as Figure 6 .

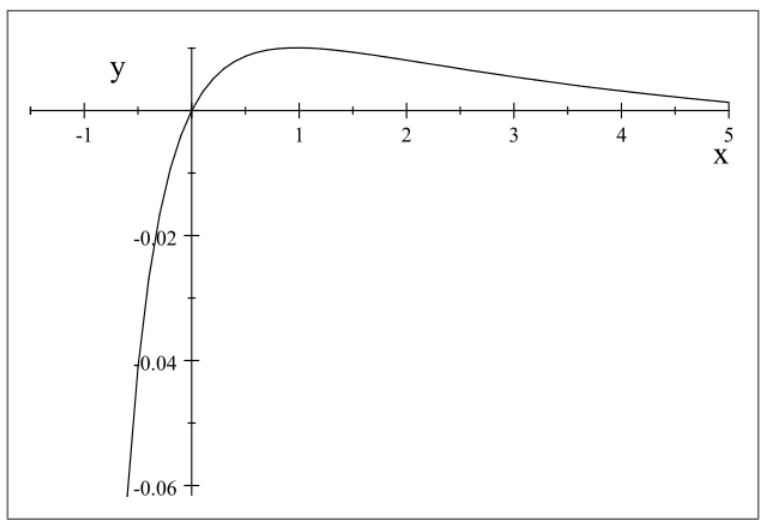

Figure 6. Difference between ${ }_{A B} F T A^{A B}$ and $G F T^{A B}$

After calculation, we find that when $t>t_{1},{ }_{A B} F T A^{A B}-G F T^{A B}>0$, where $t_{1}>500 \%$. If the degree of endowment 
asymmetry is small, for example, $\theta=0.9$ or $\theta=0.8$, it is found that when $t>t_{2},{ }_{{ }_{A} B} F T A^{A B}-G F T^{A B}>0$, where $t_{2}>300 \%$. As we have assumed that the endowments of the countries are close to symmetric so that with the tariffs these countries have patterns of trade the same as that in the symmetric case under free trade, $\theta$ cannot be too small, otherwise the whole model might not holds. And according to the external tariffs statistics, tariffs are usually under $300 \%$, so ${ }_{{ }_{A B}} F T A^{A B}-G F T^{A B}>0$ will hold, country A and B would prefer FTA to global free trade.

5. ${ }_{A B} F T A^{c}$ and $S Q^{c}$

Compare $F T A^{C}$ and $S Q^{c}$, we have

${ }_{A B} F T A^{C}-S Q^{C}=0$

$\Rightarrow\left(\frac{2 t+2}{2 t+3}\right)^{\frac{2}{3}}\left(\frac{4}{(2 t+3)(t+1)+(t+3) \theta}\right)^{\frac{1}{3}} \theta e-\frac{2}{2 t+3}(t+1)^{\frac{2}{3}}\left(\frac{t+2}{t+\theta+1}\right)^{\frac{1}{3}} \theta e=0$

$\Rightarrow \theta=-2 t-3$

Because $t>0$, then $-2 t-3<0<\theta$. So ${ }_{A B} F T A^{c}-S Q^{c}<0$, country $\mathrm{C}$ has been put in the worst place where its utility is even lower than status quo situation.

6. ${ }_{A B} F T A^{c}$ and $G F T^{c}$

Compare ${ }_{A B} F T A^{c}$ and $G F T^{c}$, we have

$$
\begin{aligned}
& { }_{A B} F T A^{C}-G F T^{C}=0 \\
& \Rightarrow\left(\frac{2 t+2}{2 t+3}\right)^{\frac{2}{3}}\left(\frac{4}{(2 t+3)(t+1)+(t+3) \theta}\right)^{\frac{1}{3}} \theta e-\left(\frac{2}{3}\right)^{\frac{2}{3}}\left(\frac{4}{(1+\theta) 3}\right)^{\frac{1}{3}} \theta e=0 \\
& \Rightarrow \theta=\left((2 t+3)(t+1)-27\left(\frac{t+1}{2 t+3}\right)^{2}\right)\left(27\left(\frac{t+1}{2 t+3}\right)^{2}-(t+3)\right)^{-1}
\end{aligned}
$$

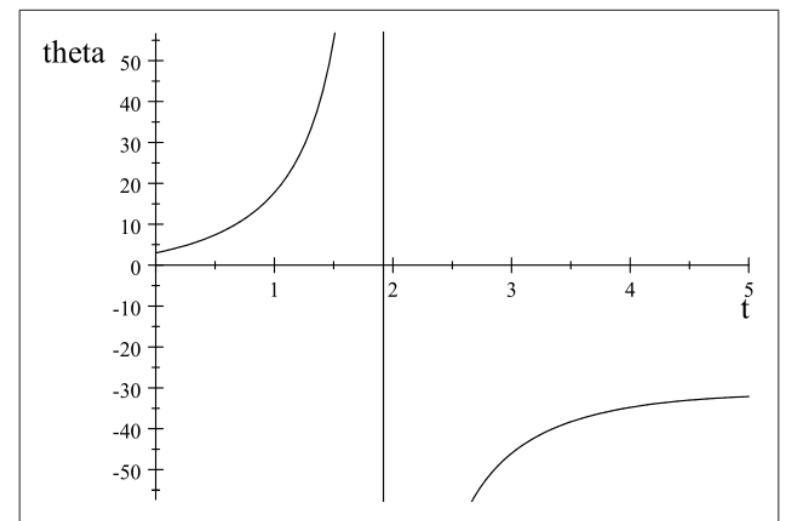

Figure 7. Difference between ${ }_{{ }_{B} B} F T A^{c}$ and $G F T^{c}$

From Figure 7, assume the asymptotic line is $t=t_{1}$. When $t<t_{1}, 27\left(\left(\frac{t+1}{2 t+3}\right)^{2}-(t+3)\right)>0$, so in the area below the curve on the left of asymptotic line, ${ }_{A B} F T A^{c}-G F T^{c}<0$, country $\mathrm{C}$ prefer global free trade. When $t>t_{1}$, $27\left(\left(\frac{t+1}{2 t+3}\right)^{2}-(t+3)\right)<0$, so in the area above the curve on the right of asymptotic line, ${ }_{A B} F T A^{c}-G F T^{c}<0$, country C prefer global free trade. We only consider the case with $t>0$, when $\theta<1$, i.e., country $\mathrm{C}$ has a smaller endowment, country $\mathrm{C}$ prefer global free trade whatever tariff level in the status quo is.

7. ${ }_{1 c} F T A^{\wedge}$ and $S Q^{\wedge}$

For country A, compare ${ }_{1} F T A^{A}$ and $S Q^{\wedge}$, we have

$$
\begin{aligned}
& { }_{A C} F T A^{A}-S Q^{A} \\
& =e\left(t^{2} \theta^{2}+7 t^{2} \theta+4 t^{2}+4 t \theta^{2}+20 t \theta+12 t+3 \theta^{2}+12 \theta+9\right) H-\left(\frac{1}{t+\theta+1}\right)^{\frac{1}{3}}\left(\frac{t+1}{t+2}\right)^{\frac{2}{3}}\left(\frac{2 t+\theta+3}{2 t+3}\right) e
\end{aligned}
$$


If $\theta=0.5$, the difference can be graphed as follow, where the curve pass through the origin.

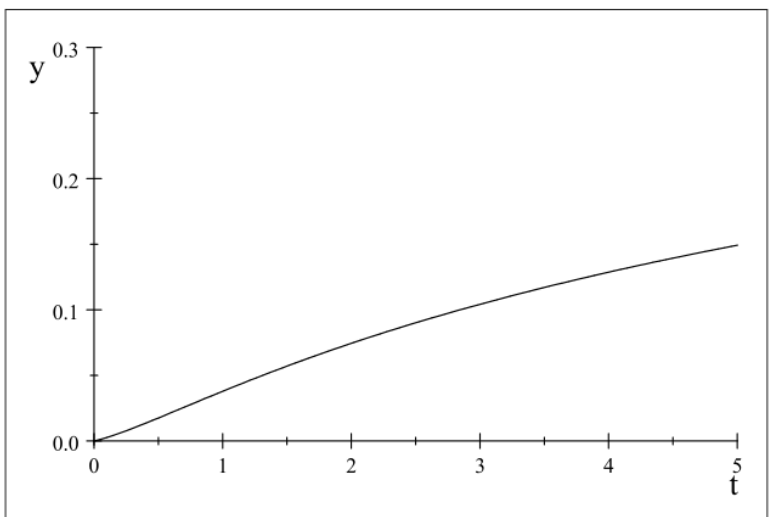

Figure 8. Difference between ${ }_{A c} F T A^{A}$ and $S Q^{A}$

From Figure 8, we find that ${ }_{A C} F T A^{A}-S Q^{A}>0$. If the degree of endowment asymmetry is small, for example, $\theta=0.9$ or $\theta=0.8$, the condition still holds. So ${ }_{A C} F T A^{A}-S Q^{A}>0$, country A's utility is higher under A-C FTA case than status quo, it has incentive to form a FTA with country $\mathrm{C}$.

8. ${ }_{A C} F T A^{A}$ and $G F T^{A},{ }_{A C} F T A^{C}$ and $S Q^{C},{ }_{A C} F T A^{C}$ and $G F T^{C},{ }_{A C} F T A^{B}$ and $S Q^{B},{ }_{A C} F T A^{B}$ and $G F T^{B}$, ${ }_{A C} F T A^{A}$ and ${ }_{A B} F T A^{A}$.

These comparisons use the same methods as the last comparison, so we eliminate calculation processes.

For country A, compare ${ }_{A C} F T A^{A}$ and $G F T^{A}$

${ }_{A C} F T A^{A}-G F T^{A}$

$=e\left(t^{2} \theta^{2}+7 t^{2} \theta+4 t^{2}+4 t \theta^{2}+20 t \theta+12 t+3 \theta^{2}+12 \theta+9\right) H-\left(\frac{1}{(1+\theta)}\right)^{\frac{1}{3}}\left(\frac{3+\theta}{3}\right)\left(\frac{1}{2}\right)^{\frac{2}{3}} e>0$

Compare ${ }_{A C} F T A^{A}$ and $S Q^{A}$

${ }_{A C} F T A^{A}-S Q^{A}$

$=e\left(t^{2} \theta^{2}+7 t^{2} \theta+4 t^{2}+4 t \theta^{2}+20 t \theta+12 t+3 \theta^{2}+12 \theta+9\right) H-\left(\frac{1}{t+\theta+1}\right)^{\frac{1}{3}}\left(\frac{t+1}{t+2}\right)^{\frac{2}{3}}\left(\frac{2 t+\theta+3}{2 t+3}\right) e>0$

For country C, compare ${ }_{A C} F T A^{C}$ and $S Q^{C}$

${ }_{A C} F T A^{C}-S Q^{C}$

$=e\left(8 t^{2} \theta^{2}+5 t^{2} \theta-t^{2}+20 t \theta^{2}+16 t \theta+12 \theta^{2}+12 \theta\right) H-\frac{2}{2 t+3}(t+1)^{\frac{2}{3}}\left(\frac{t+2}{t+\theta+1}\right)^{\frac{1}{3}} \theta e>0$

Compare ${ }_{A C} F T A^{C}$ and $G F T^{C}$

${ }_{A C} F T A^{A}-G F T^{C}$

$=e\left(8 t^{2} \theta^{2}+5 t^{2} \theta-t^{2}+20 t \theta^{2}+16 t \theta+12 \theta^{2}+12 \theta\right) H-\frac{2 \theta}{3}\left(\frac{2}{1+\theta}\right)^{\frac{1}{3}} e>0$, when $0<t<t^{*} ;$

${ }_{A C} F T A^{A}-G F T^{C}<0$, when $t>t^{*}$. In which $0.45<t^{*}<0.5$.

For country B, compare ${ }_{A C} F T A^{B}$ and $G F T^{B}$

$$
\begin{aligned}
& A C F T A^{B}-G F T^{B} \\
& =\frac{1}{2}(\theta+3)\left(\frac{t+1}{2 t+3}\right)^{\frac{2}{3}}\left(\frac{1}{4 t+6 \theta+8 t \theta+3 t^{2} \theta+t^{2}+6}\right)^{\frac{1}{3}} e-\left(\frac{1}{(1+\theta)}\right)^{\frac{1}{3}}\left(\frac{1}{2}\right)^{\frac{2}{3}}\left(\frac{3+\theta}{3}\right) e<0
\end{aligned}
$$

Compare ${ }_{A C} F T A^{B}$ and $S Q^{B}$

$$
\begin{aligned}
& { }_{A C} F T A^{B}-S Q^{B} \\
& =\frac{1}{2}(\theta+3)\left(\frac{t+1}{2 t+3}\right)^{\frac{2}{3}}\left(\frac{1}{4 t+6 \theta+8 t \theta+3 t^{2} \theta+t^{2}+6}\right)^{\frac{1}{3}} e-\left(\frac{2 t+\theta+3}{2 t+3}\right)\left(\frac{t+1}{t+2}\right)^{\frac{2}{3}}\left(\frac{1}{t+\theta+1}\right)^{\frac{1}{3}} e<0
\end{aligned}
$$

Compare ${ }_{A C} F T A^{A}$ and ${ }_{A B} F T A^{A}$ 


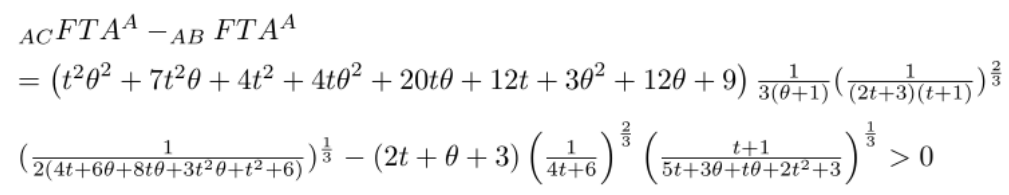

\section{Copyrights}

Copyright for this article is retained by the author(s), with first publication rights granted to the journal.

This is an open-access article distributed under the terms and conditions of the Creative Commons Attribution license (http://creativecommons.org/licenses/by/4.0/). 